$J H A$, xxxiv (2003)

\title{
ORIENTATIONS OF THE DUTCH HUNEBEDDEN
}

\author{
A. CÉSAR GONZÁLEZ-GARCÍA and LOURDES COSTA-FERRER, \\ Kapteyn Astronomical Institute, Groningen
}

\section{Introduction}

In the northern Dutch provinces of Drenthe and Groningen is a cluster of Neolithic passage graves belonging to the TRB (Tricherrandbecher, or Funnel Beaker) Culture. These form part of the Western Group, the remainder of which is found in western Germany; the other two groups are the Altmark Group in Northern Germany, and the North Group, which reaches southern Scandinavia. In the region of interest for this paper, the TRB culture is estimated to date from about 3400 to 2850 B.C. ${ }^{1}$

Although there is no good archaeological reason for considering the Dutch group in isolation from the remainder of the Western Group, we shall do so for the purposes of this preliminary study, leaving for the near future a comparative study with data from the German graves. There are 76 known sites of passage graves in the Netherlands, although some are now destroyed. ${ }^{2}$ Fifty-two sites are sufficiently well preserved for measurements to be possible.

In a flat and sandy country such as the Netherlands, it is perhaps surprising to encounter megalithic monuments with stones up to a tonne in weight. However, they are all located in an area known as the "Hondsrug", or Dog's Back, a low ridge running from the city of Groningen in the north to Emmen in the south (see Figure 1). This ridge was created as a result of glacial action, which was also responsible for depositing a number of large erratic boulders.

These monuments are known in the Netherlands as the hunebedden, or 'giants' beds'. Like other conspicuous monuments, the hunebedden have been subject to interference ever since they were built. In particular, some of their stones can be seen in nearby medieval churches. However, in 1734-35 the Province of Drenthe, concerned at the removal of stones for use in the construction of dams, passed a law to protect the monuments. In the nineteenth century, the State and the Province of Drenthe began to buy the fields where the hunebedden were located, again with the intention of protecting them. Restoration work followed, but unfortunately it was widely believed at this time that the tumuli were dunes that had arisen through natural causes and covered up the true structure of the monument. Thus, much of the 'restoration' work consisted of removing the mound to leave the stones uncovered. And this is the aspect they present today.

During the early to mid-twentieth century, many of the hunebedden were excavated, conserved and restored, by J. H. Holwerda and more especially by A. E. van Giffen. Van Giffen assigned each monument a code based on the province where they were 


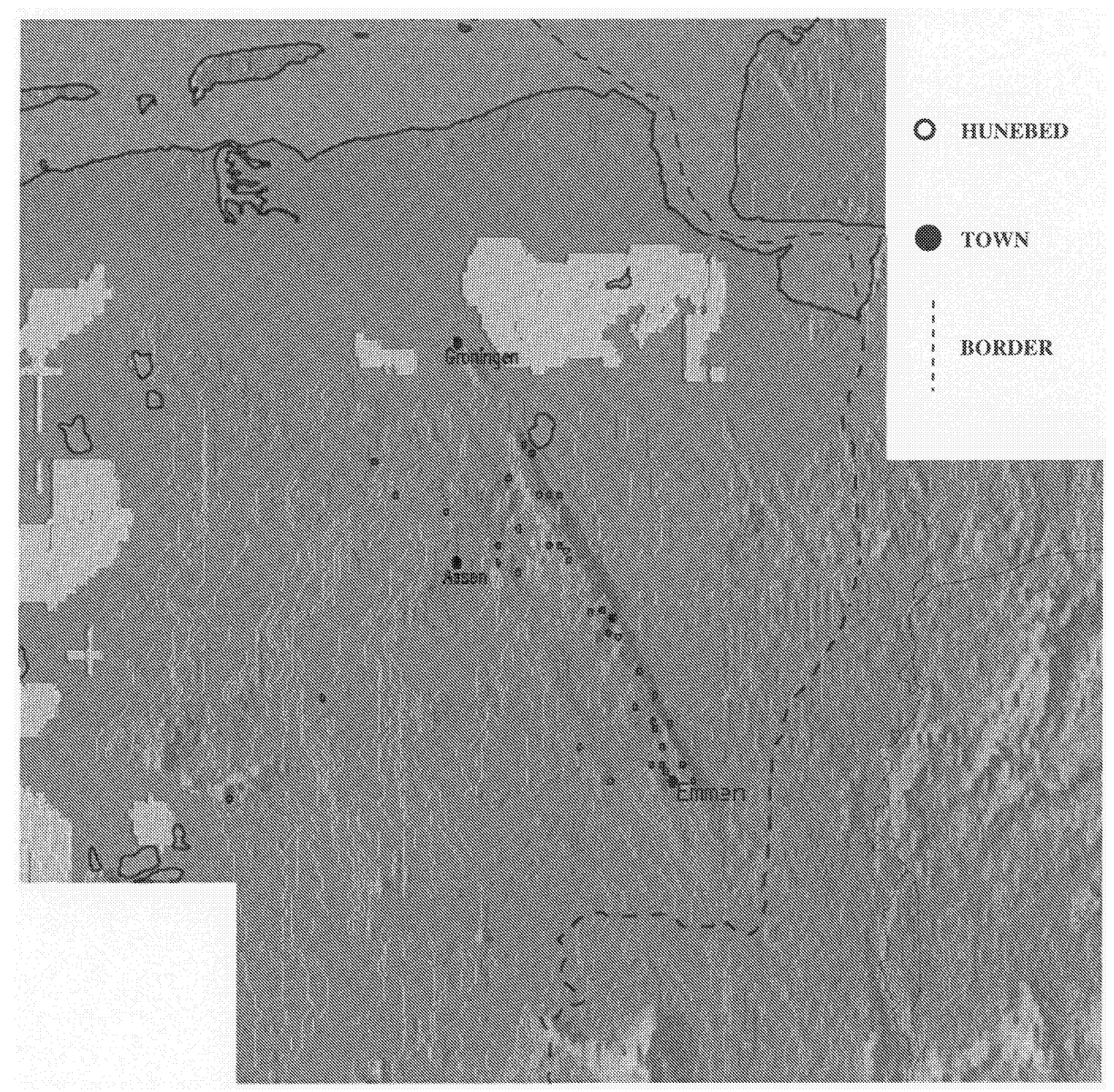

FIG. 1. The hunebedden are located on a low ridge, the "hondsrug".

located (D-Drenthe, G-Groningen) together with a number. Some of the conservation work involved considerable risk. For example, hunebed D53 in Havelte, one of the largest in the Netherlands, had to be demolished during the Second World War, by German orders, to build an airfield. Van Giffen marked all the stones and recorded their positions, and at the end of the war carefully put them all back in place. ${ }^{3}$

The state of preservation of many of the hunebedden before van Giffen came on the scene was poor. However, he managed to establish the original position of many of the stones and today most of the monuments have undergone major restoration following excavation. Of course, we must bear in mind that errors in the measurements of orientation may have been introduced as a result.

The finds resulting from these excavations and restoration were mainly fragments 
of decorated pottery. Few other remains have been found in the chamber fill, the soils in the area being too acid for human or animal remains to have survived. Offerings have been recovered from entrances to the tombs ${ }^{4}$ and these are similar to those found in Scandinavia. ${ }^{5}$

While the origins and role of these monuments within the TRB society remains a matter of debate, ${ }^{6}$ it seems clear that building them required a high degree of technological skill along with ample manpower, and this in itself implies a complex social organization. Once we start to explore their possible meanings, the question of their orientation cannot be ignored..$^{7}$ If they conformed to a common ritual tradition, or seasonal factors influenced their construction or use, then certain patterns in their orientations might be expected. This is the possibility we investigate here.

\section{The Sample}

The monuments considered here have several pairs of orthostats (from two to as many as 14 or 15) forming a chamber, which is roofed with a number of slabs. An orthostat closes each end of the chamber. The entrance is located always close to the middle of the southerly side of the hunebed. Many of the entrances have between one and three pairs of orthostats, giving to the overall monument a " $T$ " shape (see Figure 2).
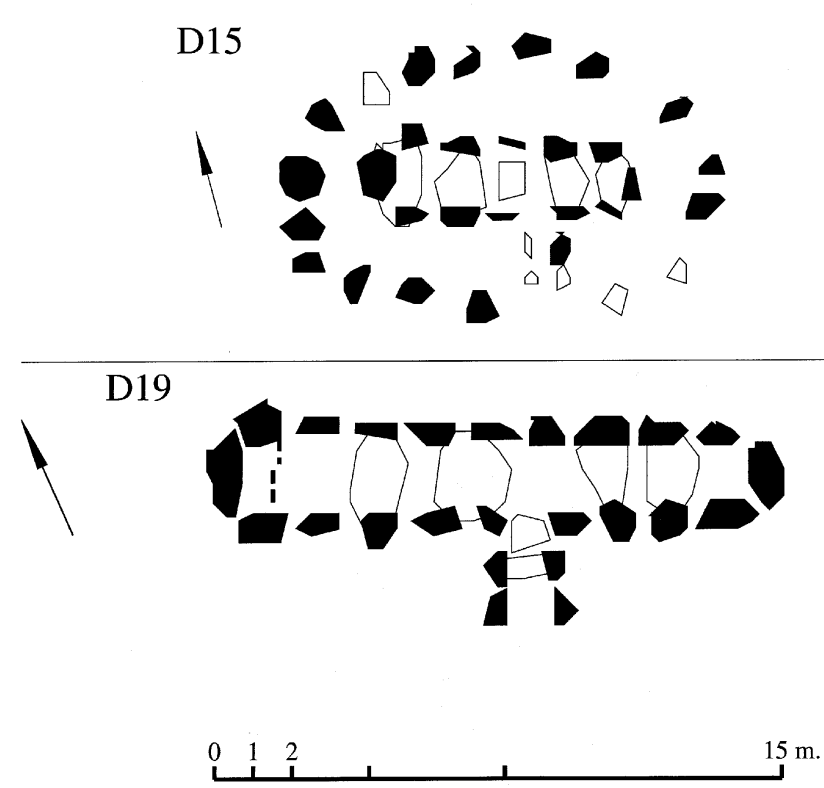

FIG. 2. Site plans for two of the hunebedden: (above) D15 is an example of a hunebed of middle size with a kerb (P-type); (below) D19 is a fairly large hunebed without kerb (N-type). In both, the entrance is in the middle of the south side and formed of several orthostats. 



FIG. 3. Two examples of hunebedden: (above) D17-Rolde is catalogued as N1, note D16 in the background; (below) D50-Noordsleen catalogued as P2, note the surrounding kerb. 
Of the 56 hunebedden catalogued by van Giffen, one (Grand Dolmen, G5 ${ }^{8}$ ) was moved to the local museum in Delfzijl shortly after its discovery in the early 1980s, to save it from destruction during the building of a factory, and of course its original orientation cannot now be measured. In Table 1 we give our measurements of the orientations of 52 of the remaining 55 hunebedden. No data are given for three sites: D33 was in such bad condition that van Giffen used some of its stones to rebuild D34 nearby; D44 (uniquely) is still on private land, and very damaged; and D48 is a huge single slab and not a hunebed as supposed by van Giffen.

In the table we give the type of passage grave, following Bakker's classification: ${ }^{9}$ $N$ denotes a simple grave without a peristaltic kerb, $P$ a grave with a kerb, and $Q$ a so-called langbett, a long-grave enclosing more than one passage grave and with a kerb. There is only one type-Q grave in the Dutch group, though others can be found in neighbouring Germany. The number (N0, N1, etc) indicates the number of pairs of orthostats marking the entrance. Orientations were measured using a precision compass and clinometer, and taken from both ends of the graves. In some cases, for example where the hunebed chamber is not straight (possibly due to errors in the reconstruction, or to shifting of the stones over time, or perhaps as originally intended) an estimate of the (larger than usual) error introduced is given. Where it was feasible to measure the orientation of the entrance, this is also given. In nearly every case the horizon altitude was close to zero, the two exceptions being the horizon in the direction of the entrance orientations at D53 and D54 ( $2^{\circ}$ and $3^{\circ}$ respectively). Measurements were corrected for magnetic declination. The last two columns give the geographical coordinates, measured with a GPS. Where this was not possible, the values have been taken from the literature and are marked with an asterisk.

\section{Location and Orientation}

In Figure 1 we show the distribution of the hunebedden in the landscape. As already mentioned, they are located within a broad band lying between Groningen and Emmen, on ground that is somewhat higher than the surroundings; in Neolithic times, it would probably have been surrounded by bogs. ${ }^{10}$ The mean elevation of this area is $12-15$ metres above sea level. Baldia ${ }^{11}$ has suggested that they are clustered around a Neolithic routeway.

Van Giffen, in $1927,,^{12}$ stated that most of the hunebedden have an east-west orientation, but he offers no statistical analysis. Baldia, ${ }^{13}$ who collected literature measurements of 2385 chambers from all over the TRB culture area, also finds no clear pattern. But lumping all the monuments together in this way would fail to reveal any practices specific to a particular locality, and furthermore he divides the circle into just 16 sectors, too coarse a bin size to reveal any detailed trends in the data.

If we plot the mean azimuths (Figure 4) of the hunebedden we can see immediately that there is a clear general trend in favour of east-west, rather than north-south, orientations. We also see a broad concentration around due east (mean $94^{\circ}$, standard deviation $3 \sigma$ ). A large proportion of the chamber orientations lie between the extreme 
A. César González-García and Lourdes Costa-Ferrer

TABLE 1. Measurement data for hunebedden.

\begin{tabular}{|c|c|c|c|c|c|}
\hline Hunebed & Type & $\begin{array}{l}\text { Chamber } \\
\text { Azimuth }\end{array}$ & $\begin{array}{l}\text { Passage } \\
\text { Azimuth }\end{array}$ & $\begin{array}{l}\text { Latitude } \\
\circ, ",\end{array}$ & $\begin{array}{c}\text { Longitude } \\
0, " 1\end{array}$ \\
\hline D1 & N1 & 79 & 161 & $* 536$ & 625 \\
\hline $\mathrm{D} 2$ & N1 & 84 & 163 & $* 534$ & 6.27 \\
\hline D3 & $\mathrm{N} 1$ & 99 & 192 & 53627 & 64021 \\
\hline D4 & N1 & 90 & 185 & 53627 & 64021 \\
\hline D5 & N1 & 106 & 194 & *53 3 & 632 \\
\hline D6 & No & 121 & & $* 535$ & 638 \\
\hline D7 & No & 81 & 167 & 53341.6 & 641 \\
\hline D8 & No & 73 & & 53336.7 & 642 \\
\hline D9 & N1 & 85 & 184 & $* 534$ & 643 \\
\hline D10 & No & 104 & & $* 532$ & 639 \\
\hline D11 & $\mathrm{N} 1$ & 112 & 193 & $* 531$ & 6.42 \\
\hline D12 & No & 146 & & $* 531$ & 643 \\
\hline D13 & No & 69 & 168 & 53041 & 64337 \\
\hline D14 & $\mathrm{P} 2$ & $99 \pm 2$ & 182 & 530007 & 64351 \\
\hline D15 & $\mathrm{P} 2$ & 112 & 194 & $* 531$ & 6.37 \\
\hline D16 & N1 & $82 \pm 2$ & 177 & $* 530$ & 637 \\
\hline D17 & N1 & 108 & 206 & 525923.5 & 63858.9 \\
\hline D18 & N1 & 87 & 178 & 525925.6 & 63859.9 \\
\hline D19 & $\mathrm{N} 2$ & 119 & 205 & 52578.3 & 6479.2 \\
\hline D20 & $\mathrm{P} 2$ & 96 & 184 & 52578.1 & 64710.6 \\
\hline D21 & N1-0 & $46 \pm 2$ & & 525640.2 & 6483 \\
\hline D22 & No & 73.5 & & 525640.7 & 6483.4 \\
\hline D23 & No & $95.5 \pm 2$ & & 525640.8 & 64819.7 \\
\hline D24 & NO & 89.5 & & 525640.8 & 64819.7 \\
\hline D25 & No & 72.5 & & 525640.6 & 64819.7 \\
\hline D26 & $\mathrm{P} 2$ & 66 & 155 & $* 5257$ & 646 \\
\hline D27 & $\mathrm{N} 2$ & 109.5 & 201 & 525548 & 64748 \\
\hline D28 & No & 99 & & 525534.4 & 64842.2 \\
\hline D29 & N1 & 71 & 162 & 525333.5 & 64843.2 \\
\hline D30 & N1 & 170.5 & 78.5 & 525330.5 & 65047 \\
\hline D31 & N1 & 119 & 202 & 52525 & 65216.6 \\
\hline D32 & No & 68 & & 525125.3 & 65023.7 \\
\hline \multicolumn{6}{|l|}{ D33 } \\
\hline D34 & N1 & 138.5 & 230 & 525034.3 & 6525 \\
\hline D35 & No & 89.5 & & 52507.7 & 65216.7 \\
\hline D36 & N1 & 104.5 & 193 & 525024.1 & 65342.5 \\
\hline D37 & No & 99 & & 525024 & 65343.6 \\
\hline D38 & N1 & 44 & 143 & $* 5249$ & 653 \\
\hline D39 & No & 25 & & $* 5249$ & 653 \\
\hline D40 & N1 & 163.5 & 77 & $* 5249$ & 653 \\
\hline D41 & No & 72.5 & & $* 5248$ & 653 \\
\hline D42 & No & $129.5 \pm 2$ & & $* 5248$ & 653 \\
\hline D43N & Q1 & 17.5 & 98 & 524736.2 & 65315.2 \\
\hline D43S & Q1 & 17.5 & 99 & 524736.2 & 65315.2 \\
\hline \multicolumn{6}{|l|}{ D44 } \\
\hline D45 & $\mathrm{P} 2$ & 77.5 & 174 & $* 5248$ & 655 \\
\hline D46 & No & 96 & & *52 47 & 656 \\
\hline D47 & No & 159.5 & & $* 5247$ & 656 \\
\hline \multicolumn{6}{|l|}{ D48 } \\
\hline D49 & $\mathrm{P} 2$ & 117 & 215 & $* 5249$ & 645 \\
\hline D50 & $\mathrm{P} 2$ & $87.5 \pm 2$ & 177 & $* 5247$ & 648 \\
\hline D51 & $\mathrm{N} 2$ & 72.5 & 160 & $* 5247$ & 648 \\
\hline D52 & N1 & 55 & 152 & $* 5252$ & 620 \\
\hline D53 & $\mathrm{P} 2$ & 74 & 163 & $* 5248$ & 613 \\
\hline D54 & N1 & 112 & 197 & $* 5248$ & 613 \\
\hline G1 & N2 & $120 \pm 2$ & 210 & 53657 & 63930 \\
\hline
\end{tabular}



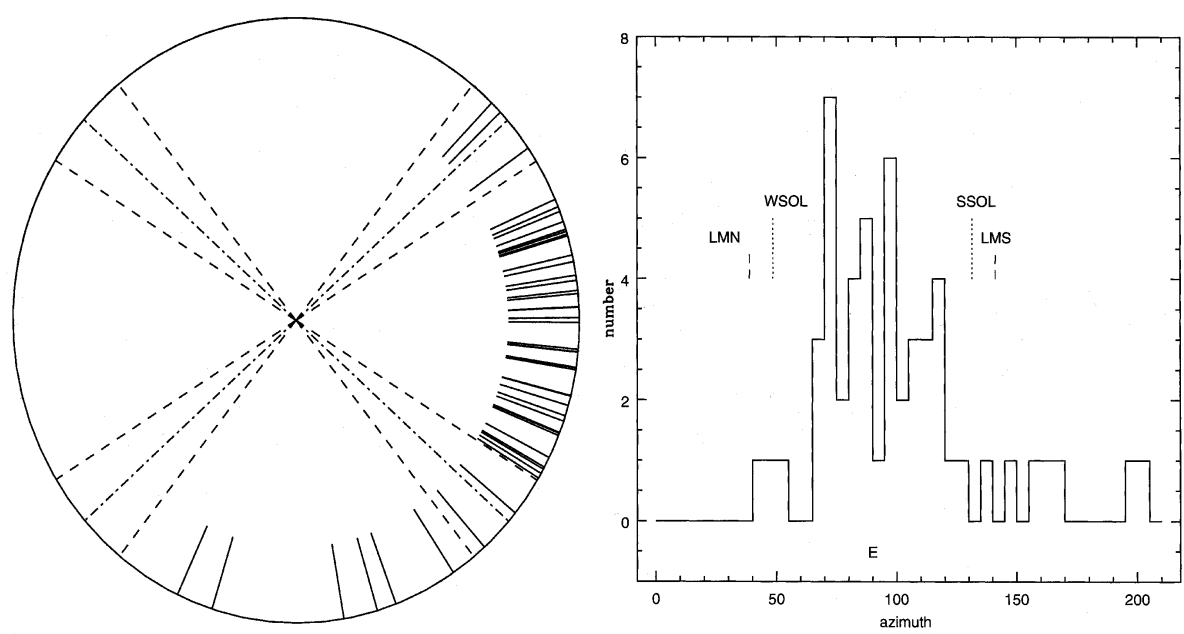

FIG. 4. Azimuth of the chambers. Most lie within the range of sunrise/sunset and moonrise/moonset. The figure on the left shows the eastern azimuth for each chamber; dashed lines indicate the extreme positions of the moon while dotted-dashed lines indicate the solstices. The figure on the right shows a histogram with the same data.

positions of sunrise (and sunset, a range of 83\%) and moonrise (and moonset, 88\%). On the other hand, while Reijs ${ }^{14}$ has claimed more specific alignments upon particular rising and setting points of the sun and moon, such as full moonrise immediately before the equinox, the same author admits that his explanation lacks consistency, and we find no evidence to support these detailed claims. On the other hand, the pattern of orientations is fully consistent with the sun rising/climbing//descending/setting model proposed by Hoskin. ${ }^{15}$

When the passage graves were built, the chambers were covered with an earthen mound that in many cases was elliptical or kidney-shaped, the mound being added after the chamber had been completed. It is possible that the chamber was oriented towards the sun or moon on the day of construction, even though the view in that direction would have been physically impossible after the tomb was covered.

Offerings were made at the entrance after construction of the monument ${ }^{16}$ indicating a ritual practice there. The entrance was open, and as previously mentioned is always located on the southerly side of the tumulus, which would be in accordance with the avoidance of northerly directions proposed by Hoskin.

\section{Acknowledgements}

The authors wish to thank Juan Belmonte and Clive Ruggles for their support and useful comments in the preparation of this text. We are also grateful to Jorge Jimenez for stimulating discussions, to Max Baldia for making available his Ph.D. thesis as well as for maintaining a fruitful dialogue, and Jacquie Keane for carefully reading and correcting our English. 


\section{REFERENCES}

1. J. A. Bakker, The Dutch hunebedden, megalithic tombs of the funnel beaker culture (International Monographs in Prehistory; Michigan, 1992), 40; M. O. Baldia, "A spatial analysis of megalithic tombs", Ph.D. dissertation, Southern Methodist University, Dallas, 1995, electronic version available at http://www.comp-archaeology.org/010Spatial_Analysis_MEGT_TOC.htm, chap. 1.

2. Bakker, op. cit. (ref. 1), 3.

3. Bakker, op. cit. (ref. 1), 8 .

4. Bakker, op. cit. (ref. 1), 58.

5. B. Hårdh and C. Roslund, "Passage graves and the passage of the moon", Acta archaeologica Lundensia, viii (1991), 35-43.

6. M. O. Baldia, "Megalithic tombs and interregional communication", unpublished paper delivered at the International Symposium: Megaliths and Social Geography, Falköping, Sweden, 1994, found via http://www.comp-archaeology.org/Falbytxt.htm; idem, op. cit. (ref. 1).

7. Michael Hoskin, Tombs, temples and their orientations: A new perspective on Mediterranean prehistory (Bognor Regis, 2001).

8. Bakker, op. cit. (ref. 1), 12.

9. Ibid.

10. J. A. Bakker, "On the possibility of reconstructing roads from the TRB Period", Berichten van de Rijksdienst voor het Oudheidkundig. Bodemonderzoek, xxvi (1976), 63-91.

11. Baldia, op. cit. (ref. 6).

12. A. E. van Giffen, De Huneebedden in Nederland (Utrecht vol. i, 1925; vol. ii, 1927; atlas-vol., 1925), pp. 155-7.

13. Baldia, op. cit. (ref. 2), chap. 15.

14. V. Reijs, http://www.iol.ie/ geniet/eng/, 1997.

15. Hoskin, op. cit. (ref. 7), passim.

16. Bakker, op. cit. (ref. 1), 58. 